\title{
Measuring the Canal Length - A Review
}

\author{
Simran Verma ${ }^{1}$, Mandeep S. Grewal ${ }^{2}$, Anshul Arora ${ }^{3}$, Ashtha Arya ${ }^{4}$, Vipul Gupta ${ }^{5}$ \\ 1, 2,3, 4, 5 Department of Conservative Dentistry \& Endodontics, SGT University, Gurugram, Haryana, India.
}

\section{ABSTRACT}

The objectives of root canal treatment are elimination of microorganisms, removal of pulpal remnants, removal of debris, and shaping of the root canal system so that it may be obturated. The most important step in endodontic therapy is canal preparation which can be achieved by accurate working length determination. Working length determines the extent of placing the instruments into the canal, it affects the degree of pain and discomfort which the patient will experience post treatment and it plays an important role in the success of the treatment if placed within correct limits.

The cementodentinal junction, where the pulp tissue changes into the apical tissue, is the ideal physiologic apical limit of WL because at this point healing is supposed to be optimal, and the wound to the periapical tissues is minimal. The apical constriction is however, histological and is impossible to locate clinically or radiographically. There are several methods of determining working length which include radiographical methods, digital tactile sense, apical periodontal sensitivity, paper point method and electronic apex locators.

The requirements of an ideal method for determining working length include rapid location of the apical constriction in all pulpal conditions, easy measurement, rapid periodic monitoring and confirmation, patient and clinician comfort, minimal radiation to the patient; ease of use in special patients; and cost effectiveness. To achieve the highest degree of accuracy in working length determination, a combination of several methods should be used. This article reviews the different methods to determine WL and their clinical implications.
Corresponding Author: Dr. Simran Verma, Department of Conservative Dentistry \& Endodontics, Faculty of Dental sciences, SGT University, Gurugram, Haryana, India.

E-mail: simranverma65@gmail.com

DOI: $10.14260 / j e m d s / 2021 / 575$

How to Cite This Article:

Verma S, Grewal MS, Arora A, et al. Measuring the canal length - a review. J Evolution Med Dent Sci 2021;10(33):28242829, DOI: $10.14260 /$ jemds/2021/575

Submission 03-04-2021,

Peer Review 10-07-2021,

Acceptance 16-07-2021,

Published 16-08-2021.

Copyright (c) 2021 Simran Verma et al. This is an open access article distributed under Creative Commons Attribution License [Attribution 4.0 International (CC BY 4.0)]

\section{KEY WORDS}

Working Length, Apex Locator, Radiographic Method. 


\section{BACKGROUND}

Measuring the working length (WL) correctly is an important part of successful root canal treatment. WL is the "The distance from a coronal reference point to the point at which canal preparation and obturation should terminate." as defined by the American association of Endodontics Glossary of Endodontic Terms 1998. Identifying this measurement incorrectly may end up in unfavorable treatment outcomes, which can include accidental extrusion of irrigant, dressing or filling and persistent periapical infection, postoperative pain and increased patient discomfort. The cementodentinal junction (CDJ) is the ideal physiologic apical limit of WL. It is the point where the pulp tissue changes into the apical tissue, also referred to as the minor diameter or the apical constriction..$^{1-4}$ Apical constriction is the optimal termination point for preparation and obturation because at this point healing is optimal, and the wound to the periapical tissues is minimal. 5 The apical constriction is however, histological and is impossible to locate clinically or radiographically. Hence, different guidelines and techniques are available to clinicians in mastering working-length determination and success is achieved when multiple methods are used. This article reviews the different methods to determine WL and their clinical implications.

\section{APICAL TERMINATION OF PREPARATION}

There are two concepts in endodontics regarding the extent of apical limit of preparation and obturation. The Scandinavian concept of preparation is to leave it 'short' with the stopping of shaping at $1-2 \mathrm{~mm}$ from the radiographic apex. The North American concept teaches shaping of the canal to the 'radiographic apex terminus'. According to Schilder's concepts, the apex is the only reliable reference point for the clinician, and the filling must reach this landmark but if the filling reaches this point, there will always be some filling material beyond the root canal system which can lead to irritation and lack of biocompatibility. Some studies suggest that it is likely that failures are more related to problems of over enlargement of the apical foramen as opposed to the presence of excess material itself. The two concepts may be combined by shaping the canal with a small foramen and a regular conical shape and, at the same time, stopping the preparation $0.5-1 \mathrm{~mm}$ short of the radiographic apex. ${ }^{6}$

Dentinocemental junction is considered as the ideal point where the preparation should terminate, as it is the transition from endodontium to periodontium but this junction is histological and is not possible to locate clinically. Apical constriction is the narrowest area of the canal that is located in the last few millimetres of the terminus. Some clinicians assume that the periodontium starts here, and consider any instrument or filling material beyond this point as over instrumentation / overfilling. For a long time, the apical constriction and dentinocemental junction were considered to be the same area and located at an average of $1 \mathrm{~mm}$ from the root apex so it was believed that WL should be determined $1 \mathrm{~mm}$ short of the radiographic apex. However, this technique is no longer reliable, because CDJ and apical constriction rarely coincide particularly in senile teeth because with advancing age, cementum deposition occurs and position of minor diameter is altered. The apical constriction is deviated linguo buccally or mesio-distally from the root and does not coincide with the anatomical apex. ${ }^{1-4}$ The thickness of the cementum also changes with pathology (apical resorption). ${ }^{6}$ Hence, apex locators should be considered essential in determining working length.

In 2000, Wu and co workers arrived at the following conclusion that with an irreversible pulpitis (vital pulp), instrumentation can be terminated at 2 to $3 \mathrm{~mm}$ short of apex. Preservation of this apical pulp stump was suggested in cases of irreversible pulpitis but with pulpal necrosis, instrumentation should be terminated at or within $2 \mathrm{~mm}$ of the radiographic apex. ${ }^{7}$ In a 10 - year clinical follow-up study, controlled over-instrumentation and obturation to the physiological foramen or apical constriction in all pulpal diagnostic states were done and it was concluded that healing occurred successfully. ${ }^{8}$ Azim and associates reviewed radiographically 422 roots with a mean follow-up of 2 years. It was found that when the roots were instrumented apically within $0.5 \mathrm{~mm}$ from the radiographic apex, the outcome was significantly more favourable (88\%). The roots that were instrumented more than $2 \mathrm{~mm}$ short from the radiographic apex had the least favourable outcome (33\%). Healing was delayed in teeth with overextended obturations by almost 14 months. ${ }^{9}$

\section{RADIOGRAPHIC METHODS}

Methods needing the formulas to calculate WL are not utilized anymore. The most commonly employed radiographic WL determination method is that of Ingle. ${ }^{10}$ Mainly, there are two radiographic exposure techniques used for conventional and digital intraoral radiography; the bisecting angle and paralleling technique. Chunn et al. reported that the paralleling and bisecting angle techniques gave comparable WLs and the slightly better performance of the former would be clinically irrelevant. ${ }^{11}$ The likelihood of over instrumentation and overfilling with the bisecting angle technique is high, as it depicts a shorter than actual file tip position, resulting in longer adjustments than required. 12

The first intraoral digital radiography system introduced was Radiovisiography (RVG; Trophy Radiologie, Vincennes, France). ${ }^{13}$ The benefits of these machines over standard radiographs are radiation exposure is minimal, speed of image acquisition and that the image can be enhanced or altered. (Shearer et al. 1991). In a study, Radiovisiography (RVG) imaging was compared with conventional radiography in determining endodontic file length adjustment and it was found that RVG was not significantly better than conventional radiography. ${ }^{14}$ In an in-vitro study, it was found that the certainty of digital radiography was comparable with conventional radiography in measuring WL. ${ }^{15}$ Another study compared the accuracy of conventional radiography (CR), radiovisiography (RVG) and electronic apex locator (EAL) and found out that WL measurements were $95.1 \%$ accurate for EALs, $75.6 \%$ accurate for RVG and $75.6 \%$ for CR within the acceptable range of $\pm 0.5 \mathrm{~mm} .{ }^{16}$ Radiographic determination of WL has been used for many years but it provides a 2D image of a 3D structure and is technique sensitive. Interpretation of 
radiographs becomes challenging when the apical foramen exits mesio-distally or bucco-lingually. Moreover, visualization of root canal files becomes tough when bone density is high and the anatomical structures come in way, that make the apex ambiguous. The zygomatic arch superimposes on $20 \%$ of maxillary first molar apices and $42 \%$ of second molar apices and interferes with the WL determination radiographically (Tamse et al. 1980). ${ }^{16}$ However, the preoperative radiograph is crucial in endodontics because it helps in determining the presence of disease, acts as an initial guide for determination of $\mathrm{WL}$, helps in understanding the anatomy of the root canal system, the number of roots and their curvature. The electronic apex locator, allows for much greater accuracy of WL determination when used with different angulated radiographs. ${ }^{17}$

\section{ELECTRONIC APEX LOCATORS}

Custer in 1918 investigated the electronic method of WL determination which was then studied further by Suzuki in 1942. He studied the flow of direct current through the teeth in the dogs. It was discovered by him that the electrical resistance between an electrode applied to the oral mucous membrane and the root canal instrument inserted into a root canal showed a consistent value of approximately $6.5 \mathrm{k} \Omega$. Sunada reported that the electrical resistance between the periodontium and the mucous membrane was consistent, and it does not depend on the age of the patients or the shape and type of the teeth.

\section{The First Generation}

The first generation apex locators used resistance method for measuring the WL. The Root Canal Meter (Onuki Medical Co., Tokyo, Japan) was the first apex locator that was developed in 1969.16 When compared with radiographs, these devices were found to be unreliable. Patients also experienced pain due to high current machine. Presence of strong electrolytes such as endodontic irrigants, haemorrhage, pus or pulp tissue led to inaccurate results. E.g. Endodontic meter, Dentometer and Endo Radar.

\section{The Second Generation}

In the second generation apex locators, impedance was utilized instead of resistance. In 1971, Sono-Explorer (Hayashi Dental Supply, Tokyo, Japan) was developed which needed to be calibrated at the periodontal pocket of each tooth. E.g. Sono -Explorer, Endocator, Apex finder, Endoanalyzer, Digipex, Digipex II, Formation IV. All suffered same issues of erroneous readings when electrolytes were present in the canals and even when the canals were dry. ${ }^{13}$

\section{The Third Generation}

In the third-generation apex locators multiple frequencies were used to measure the WL in the canals. The Apit (Endex, Osada Electric Co., Tokyo, Japan) can measure WL of the canal even with the presence of electrolytes but needs to be calibrated in each canal. Kobayashi et al. (1991) introduced the ratio method and developed the self-calibrating Root ZX (J. Morita, Tokyo, Japan). This device is able to measure the length no matter what the electrical conditions of the canal are and calibration in each canal is not required. [1] In an in-vitro study by Jenkins et al. the accuracy of the Root ZX was evaluated in the presence of $5.25 \%$ sodium hypochlorite, $2 \%$ lidocaine with 1:100,000 epinephrine, liquid EDTA, RC Prep, $3 \%$ hydrogen peroxide, and Peridex. The results demonstrated that deviation from actual length was obtained when $\mathrm{NaOCl}$ was present in the canal but otherwise it accurately measured the lengths to within $0.31 \mathrm{~mm}$, regardless of the irrigants. ${ }^{18}$ There are many studies that have tested Root ZX for it's accuracy in a variety of clinical conditions and it has now become a benchmark for other apex locators in the market. The Root ZX gives an accuracy of $90 \%$ to within $0.5 \mathrm{~mm}$ of the apical foramen or the CDJ. Many studies report accuracy of up to $100 \%$ if $1.0 \mathrm{~mm}$ is accepted (Pagavino et al. 1998). ${ }^{16}$ Other e.g include The Apex Finder AFA, The Neosono Ultima EZ, Justwo or Justy II (Yoshida Co., Tokyo, Japan), the Mark V Plus (Moyco / Union Broach, Bethpage, NY, USA) and the Endy 5000 .

\section{The Fourth Generation}

Similar to the third generation units, The Bingo 1020 (Forum Engineering Technologies, Rishon Lezion, Israel) uses two separate frequencies $400 \mathrm{~Hz}$ and $8 \mathrm{kHz}$. In an in-vitro study, Bingo 1020 was found to be comparable with the Root ZX as far as the reliability was concerned. A composite waveform of two signals, 0.5 and $4 \mathrm{kHz}$ are used by Elements Diagnostic Unit compared with the Root ZX at 8 and $0.4 \mathrm{kHz}{ }^{19}$ The limitations of these apex locators are that they need to be performed in partially dried canals and in heavy exudates or blood where it becomes inapplicable.

\section{The Fifth Generation}

Fifth generation apex locators work on the basis of the comparisons of the data taken from the electrical characteristics of the canal and additional mathematical processing. These devices perform extremely well in the presence of blood and exudate but in dry canals they experience considerable problems. Hence, additional liquids inserted in the canals become necessary. ${ }^{20}$

\section{The Sixth Generation}

Recently, sixth generation adaptive type apex locator has been developed which combines the advantages of the fifth and fourth generation appliances. Measurement using the adaptive apex locator eliminates the necessity of drying or moistening of the canal, while also achieving high degree of measurement precision in the presence of blood, sodium hypochlorite or while manipulating dry canals. ${ }^{[20]}$ Accuracy of Root ZX and Raypex 6 was evaluated in an in-vitro study in teeth with different apical diameters and it was concluded that these two apex locators are reliable in teeth with mature apices. Their accuracy is susceptible at foramen diameters exceeding 0.57 $\mathrm{mm} .^{21}$ 


\section{OTHER CLINICAL TECHNIQUES} OF WL DETERMINATION

The techniques are paper point method, tactile sensation and periodontal sensitivity. Periodontal sensitivity and tactile methods are not advocated these days because of poor accuracy. ${ }^{22}$ Paper points may be helpful in determining WL if the canal can be dried of any periapical fluid. When the paper point is inserted into the canal and taken out, the portion of the paper point that is dry is recorded as the length of the canal. Inflamed tissues will moisten the tip of the paper point at the level where the canal exits. This method is used for final WL determination. Rosenberg claims that this method is accurate and precise to within $0.25 \mathrm{~mm}$ tolerances. ${ }^{23,24}$ In a study, it was found that paper point method can estimate the location of apical foramen in straight canals but in curved canals and canals with different pulpal and periapical diagnoses, it is less reliable. ${ }^{22}$

\section{APICAL ROOT ANATOMY AND IT'S IMPACT ON WL}

\section{Root Resorption}

Weine's recommendations state that the WL should be $1,1.5$ or $2 \mathrm{~mm}$ short of the radiographic apex depending upon the periapical status and alveolar bone that surrounds the tooth. ${ }^{25}$ In such cases, the combination of digital - tactile sense and radiography have important limitations to estimate the ideal WL. ${ }^{26}$

According to Nguyen et al. the Root ZX works successfully in identifying the location of the apical constriction even when this anatomic landmark was altered. ${ }^{27}$ In a study by Goldberg et al. Root ZX was used to determine the WL in teeth with simulated apical root resorption and it was concluded that Root ZX could be used in such cases. ${ }^{26}$ The Dentaport ZX works differently and the manufacturer claims that it's the only thing to locate the foramen and not the constriction which is of great advantage in case of apical resorption.

\section{Open Apex}

Working length can be determined reliably with Root ZX in canals prepared to size 80 containing $\mathrm{NaOCl}$ and the dimensions of the measuring file do not affect the accuracy. By contrast, Fan et al. (2006) found that $2.5 \% \mathrm{NaOCl}$ had a significant effect on the accuracy of the Root ZX, while the Neosono Ultima EZ remained unaffected. Several in-vitro studies show that file sizes of more than 10 did not hamper with the readings when the diameter of minor constriction was upto size 60 with Root ZX, but it proved unreliable in cases of size 100 apical constriction (Herrera et al. 2007). In a study, Root ZX, Foramatron D10, Apex NRG and Apit 7 were used in determining the WL of teeth with wide apical foramen and these apex locators were unreliable when small size file was used.

A snug - fitting file is recommended to measure WL in teeth with wide apical foramen. A laboratory study by Herrera et al. (2011) revealed that Root ZX was accurate for an apical size of 60 and the size of the measuring file did not affect it's accuracy whereas better fitting files (minimum 45) should be used in cases where the apical sizes ranged from 70 to 80 . In a tactile technique using paper points evaluated by Baggett et al. (1996) a size 30 paper point is placed in the canal till resistance is felt. It was found that this method was accurate to within $1 \mathrm{~mm}$ of the radiographic diagnostic length in $95 \%$ of cases.

ElAyouti et al. (2009) proposed a tactile method in which a size $25 \mathrm{~K}$ - file bent at the tip was used but this method may be restricted to relatively straight canals. The paper point technique described by Rosenberg (2003) could also be considered for the WL determination of open apices in relatively straight canals but only to supplement initial EAL readings. ${ }^{28}$

\section{CURVED CANAL AND IT'S IMPACT ON WL DETERMINATION}

Studies have shown that WL changes often during cleaning and shaping of curved canals. Thompson \& Dummer (2000) reported that the reason for this could be minor straightening of the canal during enlargement or lack of length control by the operator. In a study, change of WL in curved molar root canals was investigated after preparation with Profile, ProTaper and K3 Rotary Nickel - Titanium instruments and it was concluded that the mean loss of WL varied from 0.28 to $0.92 \mathrm{~mm} .^{29}$ Measuring final WL is important because instrumentation shortens the canal. There is higher degree of length control during final apical instrumentation and obturation when the final WL is measured.22

In a study it was shown that there was a significant difference between actual WL and radiographic WL in curved palatal roots of maxillary molars as the degree of buccal curvature increased. Hence, WL should not be solely based on radiographic interpretation. RL appeared on the average to be shorter than the AL. ${ }^{30}$ In a study, Root ZX, Elements Diagnostic, Precision AL, Raypex 5 and radiographs were compared for determining WL in molars and apical constriction was located $69.01 \%, 50.49 \%, 65.40 \%, 43.93 \%$ and $14.59 \%$ of the time, respectively. In another study, Root ZX Mini and Canal Pro were shown to be accurate for both actual length and WL in mesial curved canals of mandibular molars. When 0.5 mark was used, the Apex ID was accurate in recording the WL. ${ }^{31}$

\section{IMPACT OF PULPAL AND PERIAPICAL STATUS ON WL DETERMINATION}

Some studies suggest that the impedance of canals with vital pulp and canals with necrotic pulp are different because the periodontal ligament is destroyed when the pulp is necrotic. Therefore, the precision and / or consistency of the EALs can also vary in these two conditions. In a study it was shown that apical constrictions can be determined with a higher accuracy when the pulp is vital (93.9\%) than when the canal is necrotic (76.6 \%) with AFA Apex Finder. ${ }^{32}$ Arora and Gulabivala reported that the accuracy for Endex and RCM mark II in case of necrotic tissue was lower than that for vital tissue. ${ }^{33}$

In a study using the Root ZX, no statistical difference was found when canal length was measured in vital and necrotic canals.(Dunlap et al.) ${ }^{1}$ but Haffner et al. found statistically 
significant differences when Root ZX and Endy were used to measure length in vital and necrotic canals. But, no differences were found for Justy II and Endox. ${ }^{34}$

In a recent systematic review, there was no significant difference found between vital and necrotic teeth in the precision of WL measurements for the EALs and it was concluded that the status of the pulp tissue does not influence the precision of electronic WL measurement. ${ }^{35}$

\section{CONCLUSIONS}

All the stages of a root canal treatment require precise measurement of WL because it changes constantly throughout the procedure. Establishing the correct WL would lead to a better prognosis because all endodontic procedures can cause a microsurgical wound that can cause inflammation of the involved site. When WL of three dimensional object is obtained from a two dimensional image, the clinician is not able to effectively cleanse, shape and obturate the root canal system. Hence, WL should not be determined from a single radiograph and apex locators should be considered as essential aids. However, radiographs with different angulations provide us with important information such as the configuration and curvatures of the roots and surrounding bone structures. Based on the current data, it is recommended to combine the application of radiographs and EALs that will assist practitioners to achieve favourable outcomes.

Financial or other competing interests: None.

Disclosure forms provided by the authors are available with the full text of this article at jemds.com.

\section{REFERENCES}

[1] Kim E, Lee SJ. Electronic apex locator. Dent Clin North Am 2004;48(1):35-54.

[2] Kuttler Y. Microscopic investigation of root apexes. J Am Dent Assoc 1955;50(5):544-52.

[3] Burch J, Hulen S. The relationship of the apical foramen to the anatomic apex of the tooth root. Oral Surg Oral Med Oral Pathol 1972;34(2):262-8.

[4] Dummer PM, Mcginn JH, Rees DG. The position and topography of the apical canal constriction and apical foramen. Int Endod J 1984;17(4):192-8.

[5] Ricucci D. Apical limit of root canal instrumentation and obturation, part 1. Literature review. Int Endod J 1998;31(6):384-93.

[6] Simon S, Machtou P, Adams N, et al. Apical limit and WL in endodontics. Dent Update 2009;36(3):146-53.

[7] Wu MK, Wesselink PR, Walton RE. Apical terminus location of root canal treatment procedures. Oral Surg Oral Med Oral Pathol Oral Radiol and Endodontol 2000;89(1):99-103.

[8] Tamarut T, Kovacevic M, Glavicic S. Influence of the length of instrumentation and canal obturation on the success of endodontic therapy. A 10-year clinical follow-up. Am J Dent 2006;19(4):211-6.

[9] Azim AA, Griggs JA, Huang GTJ. The Tennessee study: factors affecting treatment outcome and healing time following nonsurgical root canal treatment. Int Endod J 2016;49(1):6-16.

[10] Alothmani OS, Friedlander LT, Chandler NP. Radiographic assessment of endodontic WL. Saudi Endod J 2013;3(2):57-64.

[11] Chunn CB, Zardiackas LD, Menke RA. In vivo root canal length determination using the Forameter. J Endod 1981;7(11):505-20.

[12] Forsberg J. Estimation of the root filling length with the paralleling and bisecting-angle techniques performed by undergraduate students. Int Endod J 1987;20(6):282-6.

[13] Alothmani OS, Friedlander LT, Monteith BD, et al. Influence of clinical experience on the radiographic determination of endodontic WL. Int Endod J 2013;46(3):211-6.

[14] Leddy BJ, Miles DA, Newton CW, et al. Interpretation of endodontic file lengths using radio visiography. J Endod 1994;20(11):542-5.

[15] Nair MK, Nair UP. Digital and advanced imaging in endodontics: a review. J Endod 2007;33(1):1-6.

[16] Gordon MPJ, Chandler NP. Electronic apex locators. Int Endod J 2004;37(7):425-37.

[17] McDonald NJ. The electronic determination of working length. Dent Clin North Am 1992;36(2):293-307.

[18] Jenkins JA, Walker WA $3^{\text {rd }}$, Schindler WG, et al. An in vitro evaluation of the accuracy of the root ZX in the presence of various irrigants. J Endod 2001;27(3):209-11.

[19] Plotino G, Grande NM, Brigante L, et al. Ex vivo accuracy of three electronic apex locators: root ZX, elements diagnostic unit and apex locator and ProPex. Int Endod J 2006;39(5):408-14.

[20] Dimitrov S, Roshkev D. Sixth generation adaptive apex locator. Journal of IMAB-Annual Proceeding (Scientific Papers) 2009:75-8.

[21] Aydin U, Karataslioglu E, Aksoy F, et al. In vitro evaluation of root ZX and raypex 6 in teeth with different apical diameters. J Conserv Dent 2015;18(1):66-9.

[22] Marcos-Arenal JL, Rivera EM, Caplan DJ, et al. Evaluating the paper point technique for locating the apical foramen after canal preparation. Oral Surg Oral Med Oral Pathol Oral Radiol Endod 2009;108(5):e101-5.

[23] Rosenberg DB. The paper point technique. Part 1. Dent Today 2003;22(2):80-6.

[24] Rosenberg DB. The paper point technique. Part 2. Dent Today 2003;22(3):62-7.

[25] Khatavkar R, Hegde V. Importance of patency in endodontics. Endodontol 2010;22:85-91.

[26] Goldberg F, Desilvio A, Manfre S, et al. In vitro measurement accuracy of an electronic apex locator in teeth with simulated apical root resorption. J Endod 2002;28(6):461-3.

[27] Nguyen HQ, Kaufman AY, Komorowski RC, et al. Electronic length measurement using small and large files in enlarged canals. Int Endod J 1996;29(6):359-64.

[28] Kim YJA, Chandler NP. Determination of working length for teeth with wide or immature apices: a review. Int Endod J 2013;46(6):483-91.

[29] Khurana P, Nainan MT, Sodhi KK, et al. Change of working length in curved molar root canals after preparation with different rotary nickel-titanium instruments. J Conserv Dent 2011;14(3):264-8. 
[30] Kim-park MA, Baughan LW, Hartwell GR. Working length determination in palatal roots of maxillary molars. J Endod 2003;29(1):58-61.

[31] Piasecki L, Reis PJD, Jussiani EI, et al. A micro-computed tomographic evaluation of the accuracy of 3 electronic apex locators in curved canals of mandibular molars. J Endod 2018;44(12):1872-7.

[32] Pommer 0, Stamm 0, Attin T. Influence of the canal contents on the electrical assisted determination of the length of root canals. J Endod 2002;28(2):83-5.
[33] Arora RK, Gulabivala K. An in vivo evaluation of the ENDEX and RCM mark II electronic apex locators in root canals with different contents. Oral Surg Oral Med Oral Pathol Oral Radiol Endod 1995;79(4):497-503.

[34] Haffner C, Folwaczny M, Galler K, et al. Accuracy of electronic apex locators in comparison to actual length-an in vivo study. J Dent 2005;33(8):619-25.

[35] Tsesis I, Blazer T, Ben-Izhack G, et al. The precision of electronic apex locators in working length determination: a systematic review and meta-analysis of the literature. J Endod 2015;41(11):1818-23. 